\title{
Colorectal Cancer: Epidemiological, Clinical and Histopathological Aspects in Burundi
}

\author{
Rénovat Ntagirabiri1 ${ }^{*}$, Richard Karayuba², Gabriel Ndayisaba², Sylvain Niyonkuru2, \\ Moebeni Amani 1 \\ ${ }^{1}$ Gastroenterology Department, Kamenge University Hospital, Bujumbura, Burundi \\ ${ }^{2}$ Surgery Department, Kamenge University Hospital, Bujumbura, Burundi \\ Email: *ntagrenov@yahoo.fr
}

Received 6 February 2016; accepted 13 March 2016; published 16 March 2016

Copyright (C) 2016 by authors and Scientific Research Publishing Inc.

This work is licensed under the Creative Commons Attribution International License (CC BY). http://creativecommons.org/licenses/by/4.0/

c) (i) Open Access

\begin{abstract}
Colorectal cancer is a major cause of morbidity and mortality throughout the world. There is no study about colorectal cancer in our country. The aim of the study was to assess epidemiological, clinical, therapeutic and histological aspects of colorectal cancer over a 10-year period (19992008) in Kamenge university hospital, Bujumbura, Burundi, by a descriptive retrospective study. A total of 37 cases of colorectal cancer, 22 males (59.5\%) and 15 females (40.5\%), mean age 50.8 years, were retrieved over the period of the study. The colorectal cancer was revealed by a rectal bleeding in 21 patients $(56.8 \%)$ and an occlusive syndrome in 5 patients $(13.5 \%)$. All patients underwent surgery. According to Dukes' stages: $27 \%$ were $A, 27 \%$ B, $19 \%$ C and $27 \%$ stage $D$. Histopathologically, 18 cases $(46.7 \%)$ were differentiated adenocarcinoma, 14 cases $(37.8 \%)$ undifferentiated adenocarcinoma, 2 cases of lymphoma and 2 cases of leiomyosarcoma. All patients underwent surgery. The hospitalization stay was a mean of 27 days. The prognosis was poor with a mortality rate of $13.5 \%$ in the hospital. In conclusion, colorectal cancer deserves awareness as a public health problem in our country.
\end{abstract}

\section{Keywords}

Colon Cancer, Adenocarcinoma, Rectal Cancer, Colorectal Cancer

\section{Introduction}

Colorectal cancer (CRC) is a major cause of morbidity and mortality throughout the world [1]. CRC and breast cancer comprised together nearly $20 \%$ of the global cancer burden [1]-[3]. CRC is the third most common cancer

${ }^{*}$ Corresponding author.

How to cite this paper: Ntagirabiri, R., Karayuba, R., Ndayisaba, G., Niyonkuru, S. and Amani, M. (2016) Colorectal Cancer: Epidemiological, Clinical and Histopathological Aspects in Burundi. Open Journal of Gastroenterology, 6, 83-87. 
worldwide and the fourth most common cause of death [2] [4]. In addition, as people continue to live longer, CRC will become an even greater public health problem worldwide. In striking contrast to the situation in the Western world, CRC seems to be rare among the population in Sub-Saharan Africa. Its distribution is heterogeneous in this geographical region and data are incomplete [5] [6]. However, several recent publications have shown a rising incidence amongst blacks Africa [5]-[7]. In Burundi, CRC would be the $3^{\text {rd }}$ digestive cancer after gastric and liver cancers, according to a small study in 1990 [8]. However, no study has been carried out about epidemiological, clinical and histological aspects of CRC in our country. In addition, there is not a cancer registry in our country. The aim of our study was to evaluate epidemiological, clinical, therapeutic and histological aspects of CRC over a 10-year period (1999-2008) in Kamenge university hospital, Bujumbura, Burundi.

\section{Patients and Method}

Site of the study: The study was carried out in Kamenge university hospital, the public and national referral hospital, with a capacity of 2275 admissions per year in the surgery department. It is also the one hospital with a histopathological laboratory in Burundi.

Study population: The study population consisted of all patients attending medical care's in Kamenge university hospital since January 1999 to December 2008 for CRC. We included only patients with CRC diagnosed on basis of histological evidence before or after surgery.

Study design: This is a retrospective study highlighting the age, sex, clinical features, operations performed and histopathological subtypes of patients who had surgery in Kamenge university hospital. Cases of CRC that have been histologically confirmed were retrieved from medical files and included for the study analysis. Patients with histological data missing or data outliers were excluded. Data were collected initially in a specialized data collection form, introduced into a Microsoft Excel worksheet, and finally transferred to the statistical package for social sciences (SPSS) version 10.0 for analysis. Proportions are given with their confidence interval 95\% (CI); p value $<0.05$ was considered as statistically significant.

Ethical consideration: The ethics committee of Kamenge university hospital approved the study.

\section{Results}

A total of 37 cases of CRC were retrieved over the period of the study. There were 22 males (59.5\% CI: 43\% $74 \%$ ) and 15 females (40.5\% CI: 26\% - 57\%), sex ratio of 1.4. The mean age was 50.8 years, extremes of 19 years and 78 years. There was no difference between mean age of males and females ( $p>0.05)$. The distribution of CRC according to age is summarized in Table 1 . The annual frequency was estimated to 3,7cases per year.

Clinical aspects: The CRC was revealed by rectal bleeding in 21patients (56.8\% CI: 41\% - 71\%) and occlusive syndrome in 5 patients (13.5\%, CI: 6\% - 28\%). Abdominal pain and constipation were the major symptoms. Abdominal mass, hepatomegaly or ascites were found among 10 patients (27\% CI: 15\% - 43\%). Only 15 patients (40.5\% CI: 26\% - 57\%) consulted within 6 months since the beginning of the symptoms. The median of duration was 20 months between the beginning of symptoms and the first medical visit.

Diagnosis on colonoscopy: Macroscopically, 19 patients (51.4\% CI: 35\% - 67\%) had a burgeoning tumor, 9 patients (24.3\% CI: 13\% - 40\%) an ulcero-burgeoning tumor and 9 patients (24.3\% CI: 13\% - 40\%) had an ulcero-infiltrating tumor. There was a complete stenosis among 7 patients $18.9 \%$ (CI: 9\% - 34\%). The tumor' localizations were: 11 cases (29.7\% CI: 17\% - 46\%) in the right colon; 9 cases (24.3\% CI: $13 \%$ - 40\%) in the left colon and 17 cases (46\% CI: 31\% - 62\%) in the rectum. Precisely for the rectal cancer, 7 cases were located in the superior rectum, 9 cases in the middle rectum and 1case in the inferior rectum.

Histopathology: We retrieved 32 cases (86.5\% CI: 72\% - 94\%) of adenocarcinoma. 18 cases (46.7\% CI: 33\% - 64\%) were differentiated 14 cases (37.8 CI: 24\% - 54\%) undifferentiated. Two cases were lymphoma and 2 cases were leiomyosarcoma.

Table 1. Distribution of colorectal cancer according to age.

\begin{tabular}{ccc}
\hline Age (years) & Number of cases & Frequency $\%$ \\
\hline$<20$ & 1 & 2.7 \\
$20-39$ & 10 & 27.1 \\
$40-59$ & 13 & 35.1 \\
$>59$ & 13 & 35.1 \\
\hline
\end{tabular}




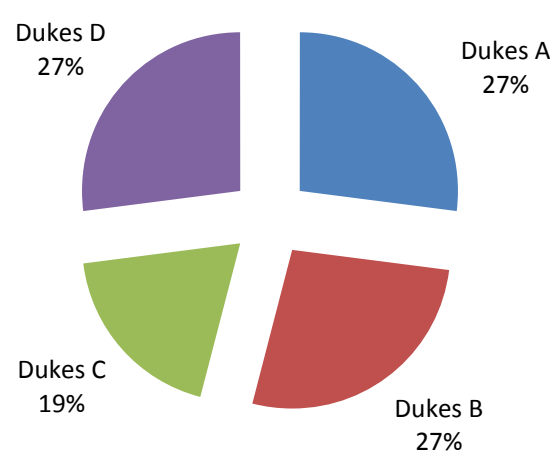

Figure 1. Distribution of patients according to Dukes' staging system.

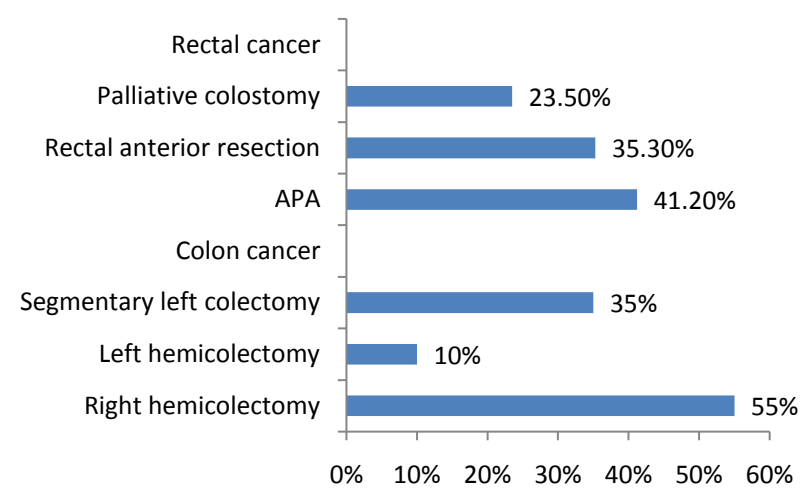

Figure 2. Surgical treatment according to rectal and colon cancer.

Treatment and outcomes: All patients underwent surgery. The stage of the CRC according to Dukes' staging system is given in the Figure 1 and the surgical procedures are detailed in Figure 2. Abdomino-perineal amputation (APA) was the mostly done in rectal cancer.

The hospitalization stay was an average of 27 days. The mortality rate in the hospital was $13.5 \%$ CI: 5\% - 28\% by the heart failure (1 patient) and the systemic infection (4 patients).

\section{Discussion}

That is the first study highlighting the age, sex, clinical features, therapeutic aspects and histopathological subtypes of CRC in Burundi. The Kamenge university hospital was chosen for our study because it is the hospital of reference at the national level with functional services of surgery, endoscopy and histopathology laboratory. Most patients through the country are transferred there and results reflect somehow the national situation. However, as limit of the study, some patients far from Bujumbura may have been unable to attend this hospital. Although a certain drawback associated with the use of a retrospective method, the results of this first study show strong evidence that the CRC is a reality in our country. Results show that the CRC affects men and women almost equally. Other authors related the same statement [9]. Furthermore, the annual frequency is estimated to 3.7 cases per year. This corroborates the findings of a number of works in Sub-Saharan Africa that show an increasing rate of CRC. Indeed, annual frequency in Gabon is 5.1 cases, in Togo 5.7 cases and in Mali 16.1 cases per year [5] [7] [10].

Another important finding is that CRC affects also young population in our study: $27.8 \%$ were under 40 years aged. This finding supports the idea of a policy of primary or secondary prevention by screening of subjects at risk even in Africa as it is in developed countries [11]. The presence of CRC screening programs is important, even if screening may increase CRC incidence in the short term through the increased detection of prevalent cases, it reduces the incidence of CRC in the long term through the removal of precancerous polyps [12]. However, the great issue in our country, as well as in developing countries, is the lack of the newest diagnostic tools 
and therapeutic means. The qualified staffs are not widely available throughout the country. Centers with capacity to perform colonoscopy and histopathology analysis are not sufficient and have to be increased.

Consequently, the diagnosis was delayed with a median of 20 months before attending medical cares. That is why $73 \%$ were diagnosed with an advanced tumor and mortality was high. Similarly, this situation is related in most black African studies [5] [7] [10] [13]. Widely, it is estimated that 394,000 deaths from CRC still occur worldwide annually, making CRC the fourth most common cause of death from cancer [9]. In our study, as well as in developing countries, the prognosis is worse as the diagnosis is delayed.

At last, the histopathological type most frequent in our study is the same most commonly found worldwide, particularly in sub-Saharan Africa studies [5] [7] [10] [13]. As the treatment of CRC is not affordable in developing countries especially in Burundi, prevention and early detection can be the most approach to fight CRC. According to Haggar et al., appropriate dietary changes, regular physical activity, and maintenance of healthy weight, together with targeted screening programs and early therapeutic intervention could, in time, substantially reduce the morbidity and mortality associated with CRC [9]. Thus, health authorities can inspire from this to make a program to successfully fight against the CRC in our country.

\section{Conclusion}

The CRC in our country deserves a great awareness as a public health issue. In the beginning, a cancer registry and a program of CRC prevention have to be operational. Public education about early diagnosis can improve the prognosis of CRC in our country.

\section{Contribution of Authors}

R Ntagirabiri designed the study and contributed in all steps. Others authors contributed somehow in collecting data, analyzing data and in literature review.

\section{References}

[1] Boyle, P. and Ferlay, J. (2005) Mortality and Survival in Breast and Colorectal Cancer. Nature Clinical Practice Oncology, 2, 424-425. http://dx.doi.org/10.1038/ncponc0288

[2] Parkin, D., Bray, F. and Ferlay, J. (2006) Global Cancer Statistics, 2002. CA: A Cancer Journal for Clinicians, 55, 74108. http://dx.doi.org/10.3322/canjclin.55.2.74

[3] Boyle, P. and Langman, J.S. (2000) ABC of Colorectal Cancer: Epidemiology. BMJ, 321, 805-808. http://dx.doi.org/10.1136/bmj.321.7264.805

[4] Ferlay, J., Shin, H., Bray, F., Forman, D., Mathers, C. and Parkin, D.M. (2010) Estimates of Worldwide Burden of Cancer in 2008: GLOBOCAN 2008. International Journal of Cancer, 127, 2893-2917. http://dx.doi.org/10.1002/ijc.25516

[5] Diallo Owono, F.K., Nguema Mve, R., Ibaba, J.R., Mihindou, C. and Ondo N’dong, F. (2011) Aspects épidemiologiques et diagnostiques des cancers colorectaux à Libreville (Gabon). Medicine Tropical, 71, 605-607.

[6] Mohammed, A.Z., Edino, S.T., Ochicha, O., Gwarzo, A.K. and Samaila, A.A. (2008) Cancer in Nageria: A 10-Year Analysis of the Kano Cancer Registry. Nigeria Journal of Medicine, 17, $280-284$.

[7] Darré, T., Amégbor, K., Bagny, A., Sewa, E., Tchangai, B., Sakiye, A., Allasani, F., Bouglouga, O., Lawson, A.L. and Napo-Koura, G. (2014) Histo-Epidemiological Profile of the Colorectal Cancers in Togo. Journal Africain d'HépatoGastroentérologie, 8, 226-229.

[8] Kadende, P., Engels, D., Ndoricimpa, J., Ndabaneze, E., Habonimana, D., Marerwa, G., Bigirimana, V., Bazira, L. and Aubry, P. (1990) Les cancers digestifs au Burundi: premiers résultats d'une enquête menée à Bujumbura. Médecine d'Afrique Noire, 37, 552-562.

[9] Haggar, F.A. and Boushey, R.P. (2009) Colorectal Cancer Epidemiology: Incidence, Mortality, Survival, and Risk Factors. Clinics in Colon and Rectal Surgery, 22, 91-97. http://dx.doi.org/10.1055/s-0029-1242458

[10] Gaudre, N., Ly, M., Badiaga, Y., Dembele, A.K., Bathily, M., Kone, A., Diallo, Y.L. and Diallo, D.A. (2013) Epidemiological and Clinical Features of Colorectal Cancer at the Hematology and Oncology Ward of Point G in Bamako, Mali, from 2005 to 2011: 113 Cases. Mali Médicale, 28, 32-36.

[11] Roncucci, L. and Mariani, F. (2015) Prevention of Colorectal Cancer: How Many Tools Do We Have in Our Basket? European Journal of Internal Medicine, 26, 752-756. 
[12] Center, M.M., Jemal, A., Smith, R.A. and Ward, E. (2009) Worldwide Variations in Colorectal Cancer. CA: A Cancer Journal for Clinicians, 59, 366-378. http://dx.doi.org/10.3322/caac.20038

[13] Irabor, D. and Adedeji, O.A. (2009) Colorectal Cancer in Nigeria: 40 Years on. A Review. European Journal of Cancer Care, 18, 110-115. http://dx.doi.org/10.1111/j.1365-2354.2008.00982.x 